\section{Association of binocular lower visual field impairment, impaired simultaneous perception, disordered visually guided motion and inaccurate saccades in children with cerebral visual dysfunction - a retrospective observational study}

GN Dutton, A Saaed, B Fahad, R Fraser, G McDaid, $J$ McDade, A Mackintosh, T Rane and K Spowart

\begin{abstract}
The principal pathways serving higher visual function comprise the dorsal stream and the ventral stream. The dorsal stream runs between the occipital lobes and the parietal lobes and subserves the ability to process the whole visual scene and carry out visually guided movement. The ventral stream runs between the occipital lobes and temporal lobe tissue and primarily subserves visual recognition and memory. These tissues are susceptible to dysfunction in children with brain damage. We report a series of 40 children in whom damage to the brain has led to a common symptom complex affecting vision. Lower visual field loss was frequently elicited. This was associated with impaired ability to make accurate visually guided movement (particularly of the lower limbs) accompanied by impaired simultaneous perception, and in some cases, with inaccurate saccades and in others, impaired perception of movement. These features are consistent with parietal/ dorsal stream dysfunction. Difficulty recognising faces and problems with route finding (which are ventral stream functions)
\end{abstract}

were also present in a number of the children. These visual difficulties can be manifest in the presence of normal visual acuity. Recognition of these problems leads to understanding of the child's visual difficulties and facilitates adaptation of curriculum delivery at school.

Eye (2004) 18, 27-34. doi:10.1038/sj.eye.6700541

Keywords: dorsal stream; ventral stream; optic ataxia; simultaneous perception; agnosia

\section{Introduction}

The principal causes of cognitive visual impairment because of brain damage in children comprise periventricular leukomalacia (PVL), hypoxic ischaemic encephalopathy, hydrocephalus, trauma, infection (meningitis and encephalitis), and both structural and functional congenital disorders of the brain. ${ }^{1,2}$ Over $50 \%$ of children with hydrocephalus, for example, may have significant difficulties interpreting visual input. ${ }^{3}$ Occipital PVL is probably one of the commonest causes of such
The Royal Hospital for Sick Children Yorkhill, Glasgow, UK

\section{Correspondence:} GN Dutton The Royal Hospital for Sick Children, Yorkhill Glasgow G3 8SJ, UK Tel: + 441412116940 Fax: +441412010858 E mail: laura.kerr@ yorkhill.scot.nhs.uk 
visual impairment, which is frequently associated with peripheral lower visual field deficits. ${ }^{4}$ The optic radiations that subserve the lower visual field lie above and adjacent to the occipital horns of the lateral ventricles where they are susceptible to damage by PVL. The greater the degree of PVL, the greater the extent of the lower visual field loss. This suggests that the fibres serving the lowermost visual field are closest to the lateral ventricles. The optic radiations subserving the upper visual field follow a sigmoid course through the temporal lobes and are less likely to be damaged by PVL.

Two functional visual pathways responsible for cognitive visual function have been described. ${ }^{5,6}$ The ventral stream connects the occipital and temporal lobe territories, and subserves recognition of geometric and biological form, route finding and visual memory. The dorsal stream connects the occipital area with the posterior parietal cortex, which allows the mind to encompass the whole visual scene and to elect to pay attention to chosen components. The posterior parietal cortex is also thought to work in harmony with the motor cortex by subconsciously providing the action plan for visually guided movement of the limbs and body through three-dimensional space. It also interacts with frontal territory responsible for both choosing which elements of the visual scene to pay attention to and bringing about saccades to the object of interest. The ventral stream thus provides a conscious analysis and understanding of the visual world, while the dorsal stream facilitates and brings about accurate movement of the body through visual space, ostensibly at a subconscious level. The two systems are closely integrated.

Arguably, the most detailed clinical description of focal dorsal stream dysfunction in a group of adults concerns six First World War soldiers who sustained bilateral bullet/shrapnel injuries to the posterior parietal cortices, affecting the supramarginal and angular gyri and the splenium internally. ${ }^{7}$ Despite intact subjective appreciation of depth (stereopsis), none of the patients could make accurate visually guided movements, a condition first described by Balint as 'optic ataxia' in a patient who had sustained a biparietal stroke. ${ }^{8}$ One patient with intact stereopsis is quoted as saying 'I did not know the height of steps until I got my feet actually on them'. The patients were unable to accurately move their eyes to fixate upon a chosen target and they were unable to appreciate multiple visual data at the same time. Counting coins was not possible and reading was facilitated by masking off adjacent text and only showing one or two words at a time. Visual recognition (a ventral stream function) was unaffected. Lower visual field loss was seen in four of the cases.
Review of the case records of the children attending the Vision Assessment Clinic at The Royal Hospital for Sick Children, Glasgow between 1992 and 2001 has revealed a number of cases with a similar clinical symptom complex to that described by Holmes and by Balint. This comprises evidence of impaired simultaneous perception and difficulty in accurately estimating the height and position of steps. These features that were observed in combination or individually and in varying degrees were commonly associated with inaccurate fast eye movements to new locations and with impairment of the peripheral lower visual field. Other aspects of cognitive visual dysfunction were also present in a number of the patients. This paper describes the clinical features in the group of children who manifested these signs.

\section{Patients and methods}

A total of 364 children with visual dysfunction associated with cerebral pathology were seen in the Visual Assessment Clinic between 1992 and 2001. Detailed evaluation of the visual problems is conducted and practical approaches aimed at facilitating development and education are recommended. The protocol of assessment has been described previously. ${ }^{1}$ Briefly, visual acuity is measured using tests appropriate to the child's ability. Colour vision (using Ishihara plates and/or the Panel D15 test) and contrast sensitivity (using the Pelli Robson chart) are measured when possible. Visual field defects are sought using a range of confrontation strategies reliant on maintaining central attention while peripheral targets are presented, and a change in attention is elicited. Formal visual field testing was possible in only a minority of children. Eye examination and refraction were performed. Structured clinical history taking, seeking evidence of all aspects of cognitive visual function ${ }^{3}$ is carried out using a protocol developed from the initial cohort of children seen. ${ }^{1}$

All 364 sets of case records were reviewed and 40 cases were identified, in which there appeared to be a common pattern of visual dysfunction in the context of a visual acuity of $6 / 60$ or better. The features, which were present in a variety of combinations comprised (a) peripheral lower visual field impairment, (b) evidence of impaired simultaneous perception, (c) inaccuracy of visually guided movement of the limbs (in particular the legs), (d) inaccurate eye movements, and (e) impaired recognition and/or route finding. Difficulty making visually guided movement was common to all the patients. Children with quadriplegia and those with visual acuities worse than 6/60 were not included. Neither were those with reduced vision because of ocular pathology nor children under the age of 3 years. 


\section{Results}

Table 1 provides the details of the ages and clinical features in the 40 children. Figure 1 shows the radiological features of PVL in an affected child.

\section{Medical diagnosis}

In all, 15 patients had spastic diplegia, six had hemiplegia, and 18 manifested normal motor development. One child had an ataxic gait. Associated

Table 1 Medical and ophthalmic findings in the group of patients examined

\begin{tabular}{|c|c|c|c|c|c|c|c|c|c|c|c|}
\hline No. & Age (years) & Medical diagnosis & $B N V A$ & $M O$ & $S Q$ & $V / F$ & $A$ & $B$ & C & $D$ & E \\
\hline 1 & 3 & $\begin{array}{l}\text { Neonatal hypoglycaemia } \\
\text { Learning disability } \\
\text { Hemiplegia } \\
\text { MRI: PVL }\end{array}$ & $6 / 9.5$ & $\mathrm{~N}$ & LET & LFD & + & + & & & \\
\hline 2 & 3 & $\begin{array}{l}\text { Road-traffic accident, head injury } \\
\text { Learning disability } \\
\text { Normal motor development }\end{array}$ & $6 / 9.5$ & $\mathrm{~N}$ & - & $\mathrm{N}$ & + & & & & \\
\hline 3 & 5 & $\begin{array}{l}\text { Infectious meningitis } \\
\text { Normal motor development }\end{array}$ & $6 / 18$ & $\mathrm{~N}$ & LXP & $\mathrm{N}$ & + & + & + & + & \\
\hline 4 & 5 & $\begin{array}{l}\text { Speech \& motor difficulties } \\
\text { Subtle diplegia MRI: PVL }\end{array}$ & $6 / 9$ & $\mathrm{~N}$ & - & LFD & + & + & & & \\
\hline 5 & 5 & $\begin{array}{l}\text { Learning disability } \\
\text { Hypoglycaemia } \\
\text { Low birth weight } \\
\text { MRI: Occipital damage } \\
\text { Normal motor development }\end{array}$ & $6 / 60$ & $?$ & LXT & LFD & + & + & & + & \\
\hline 6 & 5 & $\begin{array}{l}\text { Cerebral palsy } \\
\text { Spastic diplegia }\end{array}$ & $6 / 9$ & IS & LET & LFD & + & + & & + & \\
\hline 7 & 6 & $\begin{array}{l}\text { Spastic diplegia } \\
\text { Twin } \\
\text { MRI: PVL }\end{array}$ & $6 / 12$ & IS & RET & LFD & + & + & & & + \\
\hline 8 & 6 & $\begin{array}{l}\text { Delayed speech and language } \\
\text { Normal motor development } \\
\text { PVL? }\end{array}$ & $6 / 9$ & IS & LET & LFD & + & + & & & \\
\hline 9 & 6 & $\begin{array}{l}\text { Mild spastic diplegia } \\
\text { PVL? }\end{array}$ & $6 / 9$ & $?$ & $\mathrm{XT}$ & LFD & + & + & + & & \\
\hline 10 & 6 & $\begin{array}{l}\text { Premature birth } \\
\text { Triplet } \\
2 \text { brothers with cerebral problems } \\
\text { Normal motor development }\end{array}$ & $6 / 5$ & $?$ & - & LFD & + & + & + & & \\
\hline 11 & 6 & $\begin{array}{l}\text { Prematurity } \\
\text { Hydrocephalus } \\
\text { Normal motor development }\end{array}$ & $6 / 6$ & $\mathrm{~N}$ & - & $\mathrm{N}$ & + & + & + & & + \\
\hline 12 & 6 & $\begin{array}{l}\text { Prematurity } \\
\text { Hydrocephalus } \\
\text { Spastic diplegia } \\
\text { PVL? }\end{array}$ & $6 / 12$ & $?$ & - & $\mathrm{HH}$ & + & & + & + & \\
\hline 13 & 6 & $\begin{array}{l}\text { Learning disability of unidentified cause } \\
\text { PVL? } \\
\text { Normal motor development }\end{array}$ & $6 / 12$ & $\mathrm{~N}$ & ET & LFD & + & + & & & \\
\hline 14 & 7 & $\begin{array}{l}\text { Cerebral palsy } \\
\text { Hemiplegia } \\
\text { MRI: PVL }\end{array}$ & $6 / 9$ & $\mathrm{~N}$ & LET & LFD & + & + & & & \\
\hline 15 & 7 & $\begin{array}{l}\text { Premature birth } \\
\text { Diabetic mother } \\
\text { Normal motor development }\end{array}$ & $6 / 5$ & IS & $\mathrm{XT}$ & $\mathrm{N}$ & + & + & + & + & \\
\hline 16 & 7 & $\begin{array}{l}\text { Progressive hydrocephalus } \\
\text { Premature birth } \\
\text { Normal motor development }\end{array}$ & $6 / 6$ & $?$ & ET & $\mathrm{N}$ & + & & + & + & + \\
\hline 17 & 7 & $\begin{array}{l}\text { Cerebral palsy } \\
\text { Premature birth } \\
\text { Mild Lt. weakness } \\
\text { Slight Rt. tremor }\end{array}$ & $6 / 12$ & $?$ & LET & $\mathrm{N}$ & + & + & & & \\
\hline 18 & 7 & Cerebral palsy & $6 / 18$ & IS & - & LFD & + & + & + & & \\
\hline
\end{tabular}


Table 1 (continued)

\begin{tabular}{|c|c|c|c|c|c|c|c|c|c|c|c|}
\hline No. & Age (years) & Medical diagnosis & $B N V A$ & $M O$ & $S Q$ & $V / F$ & $A$ & $B$ & C & $D$ & $E$ \\
\hline & & $\begin{array}{l}\text { Premature birth } \\
\text { Nonidentical twin } \\
\text { Spastic diplegia } \\
\text { CT: PVL }\end{array}$ & & & & & & & & & \\
\hline 19 & 7 & $\begin{array}{l}\text { Developmental delay } \\
\text { IVH } \\
\text { PVL? } \\
\text { Normal motor development }\end{array}$ & $6 / 12$ & NYS & ET & LFD & + & + & + & & \\
\hline 20 & 8 & $\begin{array}{l}\text { Cerebral palsy } \\
\text { Shunted hydrocephalus } \\
\text { Rt. hemiplegia }\end{array}$ & $6 / 18$ & $?$ & LXT & $\mathrm{N}$ & + & + & & & \\
\hline 21 & 8 & $\begin{array}{l}\text { Premature birth } \\
\text { CT:No abnormality in white matter, brain or ventricles } \\
\text { Normal motor development }\end{array}$ & $6 / 18$ & $?$ & - & $\mathrm{N}$ & + & + & & & + \\
\hline 22 & 9 & $\begin{array}{l}\text { Learning disability } \\
\text { Post. cerebral infarctions } \\
\text { Normal motor development }\end{array}$ & $6 / 9$ & IP & AET & LFD & + & + & & + & + \\
\hline 23 & 10 & $\begin{array}{l}\text { Cerebral palsy } \\
\text { Premature birth } \\
\text { Intracerebral haemorrhage } \\
\text { Diplegia }\end{array}$ & $6 / 9$ & $?$ & - & $\mathrm{N}$ & + & & & & \\
\hline 24 & 10 & $\begin{array}{l}\text { Haemophilus influenzae } \\
\text { meningitis at } 8 \text { months } \\
\text { Resuscitation after birth } \\
\text { Ataxic gait }\end{array}$ & $6 / 48$ & $?$ & - & LFD & + & + & & & + \\
\hline 25 & 10 & $\begin{array}{l}\text { Infective endocarditis } \\
\text { CT: Focal brain damage } \\
\text { Hemiplegia }\end{array}$ & $6 / 4$ & NYS & - & LFD & + & + & & & \\
\hline 26 & 10 & $\begin{array}{l}\text { Cerebral palsy } \\
\text { Premature birth } \\
\text { Intraventricular haemorrage } \\
\text { Spastic diplegia } \\
\text { PVL? }\end{array}$ & $6 / 24$ & NYSIS & ET & LFD & + & + & + & + & \\
\hline 27 & 11 & $\begin{array}{l}\text { Hydrocephalus } \\
\text { Occasional partial epileptic seizures } \\
\text { Normal motor development }\end{array}$ & $6 / 9$ & $?$ & ET & LFD & + & & + & & \\
\hline 28 & 11 & $\begin{array}{l}\text { Learning disability of unknown cause } \\
\text { PVL? } \\
\text { Normal motor development }\end{array}$ & $6 / 7.5$ & $?$ & RET & LFD & + & + & + & & \\
\hline 29 & 12 & $\begin{array}{l}\text { Hydrocephalus } \\
\text { Normal motor development }\end{array}$ & $6 / 9$ & NYS & - & LFD & + & + & + & & + \\
\hline 30 & 12 & $\begin{array}{l}\text { Head injury } \\
\text { Cerebral atrophy } \\
\text { Mild diplegia }\end{array}$ & $6 / 60$ & $\mathrm{~N}$ & RET & $\mathrm{HH}$ & + & & & + & \\
\hline 31 & 12 & $\begin{array}{l}\text { Cerebral palsy } \\
\text { Spastic diplegia } \\
\text { CT: PVL }\end{array}$ & $6 / 9$ & IS & LXT & LFD & + & + & + & & \\
\hline 32 & 13 & $\begin{array}{l}\text { Learninig disability } \\
\text { Dyspraxia }\end{array}$ & $6 / 4$ & IS & - & $\mathrm{N}$ & + & & & & \\
\hline 33 & 13 & $\begin{array}{l}\text { Learning disability } \\
\text { Chromosomal abnormality } \\
\text { Ataxic gait }\end{array}$ & $6 / 6$ & IS & - & LFD & + & + & & & \\
\hline 34 & 14 & $\begin{array}{l}\text { Learning disability } \\
\text { Premature birth } \\
\text { Subtle diplegia } \\
\text { PVL? }\end{array}$ & $6 / 4$ & $?$ & $\mathrm{XT}$ & $?$ & + & + & & + & + \\
\hline 35 & 14 & $\begin{array}{l}\text { Learning disability } \\
\text { Cerebral palsy } \\
\text { Hemiplegia } \\
\text { Walks independently }\end{array}$ & $6 / 9$ & $\begin{array}{l}\text { IP } \\
\text { IS }\end{array}$ & RXT & $\mathrm{HH}$ & + & + & + & & + \\
\hline 36 & 15 & Cardiac surgery at 9 months & $6 / 9$ & ? & - & $\mathrm{N}$ & + & + & + & & \\
\hline
\end{tabular}


Table 1 (continued)

\begin{tabular}{|c|c|c|c|c|c|c|c|c|c|c|c|}
\hline No. & Age (years) & Medical diagnosis & $B N V A$ & $M O$ & $S Q$ & $V / F$ & $A$ & $B$ & $C$ & $D$ & $E$ \\
\hline & & $\begin{array}{l}\text { Learning disability } \\
\text { Spastic diplegia }\end{array}$ & & & & & & & & & \\
\hline 37 & 15 & $\begin{array}{l}\text { Premature birth } \\
\text { Cerebral palsy } \\
\text { Spastic diplegia }\end{array}$ & $6 / 12$ & $?$ & LXT & LFD & + & + & & + & + \\
\hline 38 & 15 & $\begin{array}{l}\text { Premature birth } \\
\text { Cerebral palsy } \\
\text { Diplegia }\end{array}$ & $6 / 24$ & $?$ & LET & LFD & + & + & + & & + \\
\hline 39 & 15 & $\begin{array}{l}\text { Premature birth } \\
\text { Cerebral palsy } \\
\text { Diplegia }\end{array}$ & $6 / 12$ & $\mathrm{~N}$ & LXT & LFD & + & + & & + & + \\
\hline 40 & 16 & $\begin{array}{l}\text { Hydrocephalus } \\
\text { Epilepsy } \\
\text { Normal motor development }\end{array}$ & $6 / 4$ & $\mathrm{~N}$ & - & $\mathrm{N}$ & + & + & + & + & + \\
\hline
\end{tabular}

A: impaired motion through depth; B: impaired simultaneous perception; C: tendency to get lost very easily; D: impaired ability to recognize faces; E : impaired ability to see moving targets; BNVA: binocular visual acuity; MO: ocular motility; SQ: squint; V/F: visual field; IP: inaccurate pursuit eye movements; IS: inaccurate saccadic eye movements; RXT: right exotropia; NYS: nystagmus; N: normal; LET: left esotropia; LXP: left exophoria; LXT: left exotropia; RET: right esotropia; XT: exotropia; LXT: left exotropia; AET: alternating esotropia; LFD: lower visual field defect; HH: homonymous hemianopia; PVL: periventricular leukomalacia shown by CT/MRI; PVL?: suspected periventricular leukomalacia.

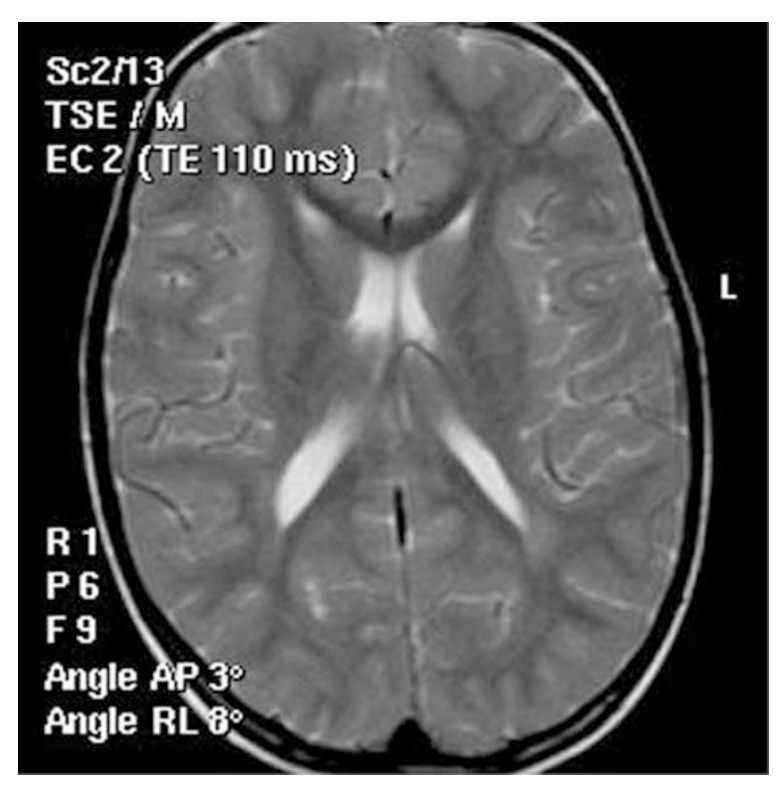

Figure 1 Axial MRI scan of a 6-year-old male twin (patient 7) born at 24 weeks (VA 6/12 right, 6/60 left because of anisometropic amblyopia) showing mild dilation of the right lateral ventricle. There is less white matter in the occipital than in the frontal areas and the parieto-occipital white matter signal is abnormal. He has slight spastic diplegia. He consistently trips over objects (indicative of lower visual field impairment), and walks into door frames and lamp posts (consistent with optic ataxia). He cannot see toys among other toys or on a patterned carpet, nor can he see objects in the distance (consistent with impaired simultaneous perception). He often misses fast-moving objects such as traffic.

conditions included learning difficulties, premature birth, chromosomal abnormalities, posterior cerebral infarction, head injury owing to road-traffic accidents, primary hydrocephalus, and meningitis. Radiologically proven PVL extending into the occipital lobes was identified in six patients. Expansion of the lateral ventricles into the occipital lobes was seen in those with hydrocephalus, and multifocal occipital damage was seen in patient 5 who sustained damage related to neonatal hypoglycaemia.

\section{Ocular examination}

The binocular visual acuity was $6 / 9$ or better in 25 cases, between $6 / 12$ and $6 / 36$ in 13 cases and 6/60 in two cases. Squint was present in 25 patients, 15 had esotropia, and 10 exotropia. Manifest nystagmus was present in four patients. Inaccurate saccades were apparent in 10 patients. Stereoacuity was measured in 14 of the 15 patients with normal eye alignment, eight had evidence of stereopsis, while six showed no stereopsis. The visual fields could be evaluated by confrontation methods in 39 patients. In 28 they were abnormal, 24 had bilateral lower visual field defects (which varied from being peripheral only, to being extensive; scotomatous loss within the lower visual field was not identified), and three showed evidence of homonymous hemianopic visual field loss. The visual fields were deemed to be normal in 12 patients. Refraction was abnormal in 15 cases. In total, 11 were significantly long sighted ( +3 dioptres or more) and four were short sighted. The remainder had normal refraction or low hypermetropia.

\section{Cognitive/perceptual visual dysfunction}

Dorsal stream dysfunction Impaired visually guided movement (Tables 1 and 2) was seen in all 40 children, six 
Table 2 Association between lower visual field defect and stereoacuity and the different features of impaired motion through three-dimensional space.

\begin{tabular}{|c|c|c|c|c|c|}
\hline Series & $S / A$ & $V / F$ & 1 & 2 & 3 \\
\hline 1 & $?$ & LFD & + & - & + \\
\hline 2 & $\mathrm{~N}$ & $\mathrm{~N}$ & + & - & - \\
\hline 3 & $\Downarrow$ & $\mathrm{N}$ & + & - & - \\
\hline 4 & $?$ & LFD & + & - & + \\
\hline 5 & ? & LFD & + & - & - \\
\hline 6 & $?$ & LFD & - & + & + \\
\hline 7 & $?$ & LFD & + & + & - \\
\hline 8 & $\Downarrow$ & LFD & + & + & - \\
\hline 9 & $\Downarrow$ & LFD & - & - & + \\
\hline 10 & $\mathrm{~N}$ & LFD & - & - & - \\
\hline 11 & $\mathrm{~N}$ & $\mathrm{~N}$ & + & - & - \\
\hline 12 & $?$ & $\mathrm{HH}$ & + & - & - \\
\hline 13 & $?$ & LFD & + & - & - \\
\hline 14 & ? & LFD & + & - & - \\
\hline 15 & $?$ & $\mathrm{~N}$ & + & + & - \\
\hline 16 & $\mathrm{~N}$ & $\mathrm{~N}$ & + & - & - \\
\hline 17 & $?$ & $\mathrm{~N}$ & + & - & + \\
\hline 18 & $\Downarrow$ & LFD & + & + & + \\
\hline 19 & $?$ & LFD & + & - & - \\
\hline 20 & $?$ & $\mathrm{~N}$ & + & - & - \\
\hline 21 & ? & $\mathrm{N}$ & + & - & - \\
\hline 22 & $?$ & LFD & + & - & + \\
\hline 23 & ? & $\mathrm{N}$ & + & - & - \\
\hline 24 & $?$ & LFD & + & - & + \\
\hline 25 & $\mathrm{~N}$ & LFD & + & - & - \\
\hline 26 & $?$ & LFD & + & + & + \\
\hline 27 & $\mathrm{~N}$ & LFD & + & - & - \\
\hline 28 & $?$ & LFD & + & - & - \\
\hline 29 & ? & LFD & + & - & - \\
\hline 30 & $?$ & $\mathrm{HH}$ & + & - & - \\
\hline 31 & $\Downarrow$ & LFD & + & + & + \\
\hline 32 & $\mathrm{~N}$ & $\mathrm{~N}$ & - & + & + \\
\hline 33 & $?$ & LFD & + & + & - \\
\hline 34 & ? & $?$ & - & - & - \\
\hline 35 & $?$ & $\mathrm{HH}$ & + & + & - \\
\hline 36 & $?$ & $\mathrm{~N}$ & + & - & - \\
\hline 37 & $\Downarrow$ & LFD & + & - & + \\
\hline 38 & $?$ & LFD & + & - & + \\
\hline 39 & $?$ & LFD & + & - & - \\
\hline 40 & $\mathrm{~N}$ & $\mathrm{~N}$ & + & - & - \\
\hline
\end{tabular}

of whom had intact stereopsis. Of the children, 35 have difficulty knowing whether a floor boundary is a step or not. The difficulties described and observed were as follows:

(1) Inability to cross previously un-encountered floor boundaries without first exploring them by touch.

(2) Lifting the foot too early or too late, too high or too low, to climb a step or kerb.

(3) Walking off the edge of kerbs without seeing them.

(4) Difficulty climbing stairs and much greater difficulty coming down. A banister is needed to provide a tactile and proprioceptive clue to the gradient.
(5) Inability to reach accurately was less commonly seen but an increased tendency to knock things over, particularly in a hurry, was typical.

These problems were manifest in the children with lower visual field defects despite their looking directly at the step or floor boundary and probably cannot be ascribed to the visual field defect per se. A history of intermittently walking into apparently obvious objects was commonly described.

Impaired simultaneous perception was observed in 33 of the children. A characteristic common to all was an inability to see an obvious feature pointed out in the distance, which could not be ascribed to reduced visual acuity (the more distant the scene, the greater the complexity and detail). Young children were unable to find a chosen toy in a toy box, or from among other toys and were regularly unable to find toys, objects or clothing when they were lying on a patterned carpet or bedspread. The majority of the children had considerable problems in busy environments such as supermarkets. Many became frightened, but there was also a group of young children who became disinhibited and difficult to control in such environments. In contrast, behaviour and attention improved in environments where there was little visual crowding such as rooms with plain decor and little clutter, or in open parkland.

For many of the older children, reading is enhanced either by enlargement or by masking of adjacent text or (in some cases) by sequential presentation of single words against a blank background on a computer screen.

Difficulty seeing moving targets or detail on moving targets was elicited in 13 children, 12 of whom had impaired simultaneous perception and impaired visually guided movement and one whose simultaneous perception was probably intact. The features exhibited by these children included:

(1) An inability to perceive detail on moving targets.

(2) A preference not to watch cartoons and other fast-moving imagery on television.

(3) An inability to see fast-moving animals such as dogs.

(4) An inability to count fingers on a moving hand unless it was moving very slowly.

Ventral stream dysfunction A tendency to get easily lost was described in 18 of the children. These difficulties included:

(1) Problems with route finding when outside.

(2) Difficulty with route finding within buildings, for example, school. 
(3) Problems with orientation within a room and not knowing which cupboard or drawer to open.

(4) Difficulty with orientation within extra-personal space (eg regularly having to be reminded where the pencil has been put down).

Difficulty recognising peoples faces was described for 13 of the children. Six of whom also had a tendency to get lost. The problems of face recognition were either complete or incomplete, when it was difficult to recognise well-known individuals out of context. Incorrect recognition of unknown people as being known was also common in this group.

\section{Discussion}

This is a retrospective observational study of a clinical practice, which included a detailed and structured history taken between 30 and $60 \mathrm{~min}$ for each child and neurological, orthoptic, and occupational therapy assessment, using a protocol that has developed over the period of study. When we reviewed the records of all the patients we had seen, a pattern emerged in which there was a group of children referred whose symptomatology closely resembled that described by Gordon Holmes in 1918 for six First World War soldiers with symmetrical bilateral posterior parietal injuries. These comprised lower visual field loss, impaired mobility through the visually perceived world, difficulty in extracting information from complex visual scenes and problems moving the eyes accurately to chosen new locations in the visual scene. ${ }^{7}$

Many of the children we describe have not undergone imaging, but in those who have, periventricular white matter damage in the occipital and superior parietal areas was a common feature. It is therefore possible that the white matter, which does not fully develop in this area includes the superior occipital radiations (serving the peripheral lower visual field) and tissues subserving dorsal stream functions. Unlike the original descriptions, in which what is now recognised as dorsal stream dysfunction was ostensibly absolute in nature, the problems described in this paper are variable in degree, perhaps because of incomplete damage and the potential for recovery in the developing brain of a child. ${ }^{1}$

Lower visual field impairment varied from being peripheral only, to affecting almost all of the lower field below the midline, but no lower scotomatous visual field loss was identified. This implies that the fibres subserving the lowermost visual field are closest to the lateral ventricles.

A simple practical test that detects peripheral field loss is to move a target forward from under the chin until it is detected by the child who is looking straight ahead. It is normally identified within $10 \mathrm{~cm}$. Children with peripheral lower visual field loss are not visually aware of their feet while walking, especially when going downhill (going uphill is much easier). An approach that introduces a strategy of 'look down, check and go' on rough and sloping ground can prove very helpful.

Presumed dorsal stream dysfunction was the common feature in the cohort studied. Inaccuracy of visually guided movement (or optic ataxia) of the lower limbs through visual space was seen in every case. In the context of mild spastic diplegia, and peripheral lower visual field loss, it is difficult to know if impaired visually guided movement of the lower limbs was truly an additional feature. However, inability to cross a floor boundary without tactile exploration and the degree of inaccuracy of leg movement were out of keeping with the mobility problems, and both could be manifest despite normal visual fields and in spite of looking directly at the ground. Affected children are helped considerably when they hold onto the elbow of an accompanying person (rather than the hand) in a manner analogous to leading the blind. Constructional dyspraxia has recently been recognised in over $90 \%$ of 35 children with preterm diplegia. ${ }^{9}$ This was not related to stereoacuity. It is possible that the authors are describing a specific dorsal stream disorder especially in the light of their recommendation that books with enough space between the lines are used for education. Children with problems of visual crowding associated with impaired simultaneous perception perform and progress better when small amounts of information are presented sequentially against a plain background. Visual perceptual training may have a role to play. ${ }^{10}$ Impaired perception of movement is also associated with dorsal stream disturbance and needs to be recognised. The implications concerning both safety in traffic and education are self-evident.

A number of the children in this study had not undergone imaging and reliance was placed on the clinical diagnosis. This was primarily because it was not felt appropriate by the parents or attending paediatrician to employ general anaesthesia to obtain information, which would not significantly influence management. In those who had undergone imaging PVL was the commonest abnormality. This accords with a similar observation that thinning of the parietal and/or occipital white matter has been observed in children with preterm diplegia and visuospatial cognitive deficits. ${ }^{4,11}$ So far, we have not found it possible to relate symptoms to the results of imaging.

In conclusion, symptomatology consistent with presumed dorsal stream pathology appears to be common in children with cerebral visual impairment and may be associated with ventral stream dysfunction. In 
future, structured investigation of this presumed pathology is warranted, including objective assessment of thresholds for perception of complex visual imagery and quantitative investigation of the accuracy of both upper and lower limb movement through threedimensional visual space along with appropriate neuroradiological imaging. A clinical approach which recognises the difficulties experienced by these children and their families and which suggests strategies that help ${ }^{12}$ is important because such children are then no longer criticised for their poor performance. Instead, appropriate measures are taken to help them.

\section{References}

1 Dutton G, Ballantyne J, Boyd G, Bradnam M, Day R, McCulloch $\mathrm{D}$ et al. Cortical visual dysfunction in children: a clinical study. Eye 1996; 10: 302-309.

2 Dutton GN, Jacobson LK. Cerebral visual impairment in children. Semin Neonatol 200; 6: 477-485.

3 Houliston MJ, Taguri AH, Dutton GN, Hajivassiliou C, Young DG. Evidence of cognitive visual problems in children with hydrocephalus: a structured clinical history-taking strategy. Dev Med Child Neurol 1999; 41: 298-306.

4 Jacobson LK, Dutton GN. Periventricular leukomalacia: an important cause of visual and ocular motility dysfunction in children. Surv Ophthalmol 2000; 45: 1-13.

5 Milner AD, Goodale MA. The Visual Brain in Action. Oxford University Press: Oxford, 1995.

6 Stasheff SF, Barton JJ. Deficits in cortical visual function. Ophthalmol Clin North Am 2001; 14: 217-242.

7 Holmes G. Disturbances of visual orientation. $\mathrm{Br} \mathrm{J}$ Ophthalmol 1918; 2: 449-468, 506-516.

8 Harvey M. Psychic paralysis of gaze, optic ataxia and spatial disorder of attention by Rudolph Balint. Cog Neuropsychol 1995; 12: 265-282.

9 Koeda T, Inoue M, Takeshita K. Constructional dyspraxia in preterm diplegia: isolation from visual and visual perceptual impairments. Acta Paediatr 1997; 86: 1068-1073.

10 Zihl J. Neuropsychological Rehabilitation, A Modular Handbook, Rehabilitation of Visual Disorders after Brain Injury. Psychology Press: East Sussex, 2001.

11 Goto M, Ota R, Iai M, Sugita K, Tanabe Y. MRI changes and deficits of higher brain functions in preterm diplegia. Acta Paediatr 1994; 83: 506-511.

12 Dutton GN. The Elridge Green Lecture 2002. Cognitive vision, its disorders and differential diagnosis in adults and children: knowing where and what things are. Eye 2003; 289-304. 